Rev. Saúde públ., S. Paulo, 18: 487-90, 1984.

\title{
UTILIZAÇÃO DA FRAÇÃo SEMIPURIFICCADA DA PROTEINASE DO TRYPANOSOMA CRUZI NO IMUNODIAGNÓSTICO DA DOENÇA DE CHAGAS*
}

\author{
Ajax Mercês Atta** \\ Angela Maria de Carvalho Pontes** \\ Maria Luiza de Souza** \\ Daria Repka*** \\ Humberto A. Rangel***
}

\begin{abstract}
ATTA, A. M. et al. Utilizaçăo da fração semipurificada da proteinase do Trypanosoma cruzi no imunodiagnóstico da doença de Chagas. Rev. Saúde públ., S. Paulo, 18: 487-90, 1984.

RESUMO: Foram sensibilizadas hemácias humanas $0 \mathrm{Rh}$ negativo com a fraçăo semipurificada (Fp) da proteinase do Trypanosome cruzi, e testadas quanto a antigenicidade com soros de pacientes portadores de tripanossomfase americana crónica e de outras doenças parasitárias não relacionadas. Reaçס̃es de hemaglutinação positivas foram observadas com os soros de pacientes chagásicos e com alguns soros de indivíduos portadores de leishmaniose cutaneomucosa. Não foram observadas reaçð̋es cruzadas com os soros de pacientes portadores de leishmaniose visceral, malária, toxoplasmose, sifilis, esquistossomose e mononucleose. Os resultados obtidos sáo favoráveis ao emprego desta fraçáo antigênica em testes de imunodiagnóstico da tripanossomiase americana.
\end{abstract}

UNITERMOS: Tripanossomíase americana, điagnóstico. Trypanosoma cruzi. Proteinase.

\section{INTRODUÇÃO}

Diferentes técnicas têm sido desenvolvidas visando o diagnóstico sorológico da doença de Chagas, em particular na sua fase crônica, onde a demonstração do Trypanosoma cruzi por métodos diretos, na maioria das vezes, não é possível (Camargo e Take$\mathrm{da}^{1}$ ). Entre estas, a hemaglutinação passiva, introduzida por Muniz (Goble ${ }^{4}$ ) no sorodiagnóstico da infecção chagásica, tem recebido especial atenção devido à sua facilidade de execução, alta sensibilidade e reprodutibilidade. $\mathrm{Na}$ busca de tornar esta reação específica para o diagnóstico laboratorial da tripanossomíase americana, diferentes antígenos, somáticos ou de membrana plasmática do $T$. cruzi, têm sido usados na sensibiliza- ção de hemácias humanas ou de origem ani. mal (Goble ${ }^{4}$ e Carniol e col. ${ }^{2}$ ). Recentemen. te, Rangel e $\mathrm{col}^{7}{ }^{7}$ isolaram uma proteinase do $T$. cruzi, que pode ser encontrada nas três formas evolutivas de diferentes cepas do parasito e capaz de digerir diferentes substratos protéicos em ampla faixa de $\mathrm{pH}$. No presente trabalho procurou-se obter informaçōes sobre a possibilidade do emprego da fração semipurificada desta proteinase para a sensibilização de hemácias, com a finalidade de imunodiagnóstico da doença de Chagas na fase crônica.

\section{MATERLAL E METODOS}

Fração semipurificada (Fp) da proteinase do

* Trabalho realizado com auxúlio parcial da FINEP. Proc. B/76/81/360/00/00

* Do Departamento de Farmácia Qualitatica da Faculdade de Farmácia da Universidade Federal da Bahia - Campus Universitário de Ondina - Rua Jereneoaba, s/no - 40.000 - Salvador, BA, Brasil.

*** Do Departamento de Microbiologia e Imunologia do Instituto de Biologia da Universidade Estadual de Campinas - Caixa Postal 6109 - 13100 - Campinas, SP - Brasil. 
ATTA, A.M. et al. Utilização da fração semipurificada da proteinase do Trypanosome cruzi no imunodiagnóstico da doença de Chagas. Rev. Saúde públ, S. Paulo, 18:487-90, 1984.

T. cruzi - Foi obtida a partir da fração solúvel de lisados delipidados de formas de cultura de $T$. cruzi da cepa y em meio LIT, ajustada para $\mathrm{pH} 4.5$ pela adição de HCL $0,1 \mathrm{~N}$, seguido de precipitação por acetona em banho refrigerado a $-599 \mathrm{C}$ sob agitação constante (Rangel e col. $^{8}$ ).

Soros humanos - Soros normais foram obtidos de individuos aparentemente sadios, com sorologia negativa para a doença de Chagas. Os soros de pacientes chagásicos procederam das seguintes instituiçð̃es: Hospital Professor Edgar Santos (UFBA) e Laboratório Central Gonçalo Moniz. Estes soros apresentaram testes positivos para a tripanossomíase americana, conforme determinado por reaçōes de fixação de complemento, imunofluorescência indireta e de hemaglutinação passiva. Soros de pacientes portadores de doenças não relacionadas à doença de Chagas foram obtidos do Instituto de Medicina Tropical da USP e do Núcleo de Medicina Tro. pical da Universidade de Brasília.

Testes de hemaglutinacão passiva - Hemá. cias humanas $0 \mathrm{Rh}$ negativo foram formolizadas segundo Csizmas $^{3}$ e tratadas com ácido tânico e sensibilizadas com o antígeno de acordo com as recomendações de Hebert ${ }^{5}$. $\mathrm{Na}$ sensibilização dos eritrócitos foram utilizados $2 \mathrm{mg}$ da Fp, dosados pelo método de
Lowry e col. ${ }^{6}$ contra um padrão de ovalbu. mina. Os testes de hemaglutinação passiva foram realizados em placas de policabonato, com o fundo em $U$, utilizando-se volumes de 50 microlitros das diluiçð̋es seriadas dos soros em salina fosfatada $0,15 \mathrm{M}, \mathrm{pH} 7.2$, contendo como estabilizador $0,4 \%$ de soro de cobaia previamente inativada e absorvido com as hemácias suportes, e volumes de 25 microlitros da suspensáo a $1 \%$ das hemácias sensibilizadas. As reações foram lidas após duas horas de incubação à temperatura ambiente, considerando-se positivos os títulos iguais ou superiores a $1 / 16$. Controles apropriados para investigar a ocorrência de aglutinação inespecífica foram constantemente incluídos nestes testes.

\section{RESULTADOS}

Foram testados 85 soros pela hemaglutinação passiva usando hemácias sensibiliza. das pela Fp. Destes, 31 soros eram de pacientes com doença de Chagas enquanto que os 54 soros restantes eram de indivíduos não chagásicos, situando-se entre estes 19 soros de pessoas sadias e 35 soros de pacientes portadores de doenças parasitárias outras, não relacionadas à tripanossomíase americana.

Os resultados destes testes, assim como a distribuição por títulos, são apresentados na Tabela 1

\section{T A B E L A 1}

Resultados das reaçōes de hemaglutinação passiva usando hemácias sensibilizadas com a Fp e soros de indivíduos sadios, chagásicos e portadores de outras doenças parasitárias

\begin{tabular}{lcccc}
\hline & No de casos & $<1 / 16$ & $\begin{array}{c}\text { Títulos } \\
1 / 16-1 / 64\end{array}$ & $1 / 128-1 / 256$ \\
\hline Pacientes & 31 & - & 24 & 07 \\
Outras doenças & 35 & 33 & 02 & - \\
Sadios & 19 & 19 & - & - \\
\hline
\end{tabular}


ATTA, A.M. et al. Utilização da fração semipurificada da proteinase do Trypanosoma cruzi no imunodiagnóstico da doença de Chagas. Rev. Saúde públ., S. Paulo, 18: 487-90, 1984.

Avaliando-se a especificidade do teste de hemaglutinação passiva frente aos soros de pacientes portadores de outras doenças, foi verificada a ocorrência de reações cruzadas com apenas dois soros testados, procedentes de indivíduos com leishmaniose cutaneomucosa.

Os demais soros, inclusive os de pacientes com calazar, não apresentaram reaçбes de hemaglutinação positivas (Tabela 2).

$\begin{array}{lllllll}\text { T } & \text { A } & \text { B } & \text { E } & \text { L } & \text { A } & 2\end{array}$

Avaliação da especificidade do teste de hemaglutinação passiva com a Fp frente aos soros de pacientes com outras doenças parasitárias

\begin{tabular}{lccc}
\hline Doenças & Nọ de casos & Positivos & Negativos \\
\hline Calazar & 8 & - & 8 \\
Esquistossomose & 3 & - & 3 \\
Leishmaniose tegumentar & 8 & 2 & 6 \\
Malária & 3 & - & 3 \\
Mononucleose & 3 & - & 3 \\
Sífilis & 7 & - & 3 \\
Toxoplasmose & 3 & & 7 \\
\hline
\end{tabular}

\section{DISCUSSÃO}

Os resultados obtidos nos testes de hemaglutinação passiva com hemácias sensibilizadas com a fração semipurificada da proteinase do $T$. cruzi são, aparentemente, favoráveis ao emprego desta fração no imunodiagnóstico da doença de Chagas. A facilidade de obtenção da $\mathrm{Fp}$, possível em laboratório de médio porte, assim como a aparente ausência de reações cruzadas, com exceção daquelas observadas com alguns soros de pacientes com leishmaniose tegumentar, justificam a realização de análises mais detalhadas da sua antigenicidade, uma vez que, como demonstrado por Rangel e col. ${ }^{\mathbf{4}}$, diferentes antígenos do $T$. cruzi estão presentes na $\mathrm{Fp}$, além de conter cerca de $66 \%$ da atividade proteinásica original dos lisados de cultura do pa. rasito. Realizando reaçőes de hemaglutinação com as hemácias sensibilizadas com a $\mathbf{F p}$ e soros antiproteinase obtidos através da imunização de coelhos com a enzima purificada, foram verificadas reações positivas, indicando a sua presença na superfície des- tas células. Estudos estão sendo conduzidos visando identificar a especificidade dos anticorpos dirigidos contra a $\mathrm{Fp}$, tanto nos soros de pacientes chagásicos como nos soros de portadores de leishmaniose cutaneomucosa que reagem cruzadamente. Provavelmente surgirão destes estudos informaçōes que possibilitem a obtenção de uma fra. ção antigênica mais específica para o diag. nóstico sorológico da doença de Chagas, do mesmo modo que poderá ser investigada a ocorrência de anticorpos antiproteinase, o que fornecerá alguns dados relativos ao papel desta enzima na patologia da tripanossomíase americana.

\section{AGRADECIMENTOS}

À Dra. Maria Emilia Amorim Ramos, Laboratório Central Gonçalo Moniz, e aos Drs. Antônio Walter Ferreira e Air Colombo Barreto, do Instituto de Medicina Tropical da USP e do Núcleo de Medicina Tropical da UNB respectivamente, por possibilitarem a aquisição de alguns dos soros utilizados no presente trabalho. 
ATTA, A.M. et al. Utilização da fração semipurificada da proteinase do Trypanosoma cruzi no imunodiagnóstico da doença de Chagas. Rev. Saúde públ, S. Paulo, 18:487-90, 1984.

ATTA, A. M. et al. [The use of a semipurified fraction of Trypanosoma cruzt proteinase in immunodiagnosis of Chagas' disease.] Rev. Saúde públ, S. Paulo, 18:487-90, 1984.

ABSTRACT: Group 0 Rh negative human erytrocytes were coated with the semipurified fraction of $T$. cruzi proteinase and tested with sera both from patients with chagas disease and from others with unrelated parasitic diseases. Positive haemagglatination reactions were only observed with the sera from the former and with that from two patients with mucocutaneous leishmaniasis. No crossed reactions were observed with visceral leishmaniasis, malaria, toxoplasmosis syphilis, schistosomiasis or mononucleosis sera. Results suggest that this purified fraction can be used in immunodiagnosis of American Trypanosomiasis.

UNITERMS: Trypanosomiasis, South American, diagnosis. Trypanosoma cruzi. Peptide peptidohydrolases.

\section{REFERENCLAS BIBLIOGRÅFICAS}

1. CAMARGO, M. E. \& TAKEDA, G. K. F. Diagnóstico de laboratório. In: Brener, $Z$. \& Andrade, Z.A. Trypanosoma cruzi e Doenças de Chagas. Rio de Janeiro, Gua-. nabara Koogan, 1979. p. 175-98.

2. CARNIOL, C.; NEVES, M.; ZINGALES, B.; ARAUJO, P. S. \& COLLI, W. Plasma membrane origin of Trypanosoma cruzi antigenic determinants in Chagas' disease. Rev. Inst. Med. trop. S. Paulo, 24: 83-7, 1982.

3. CSIZMAS, L. Preparation of formolinized erythrocytes. Proc. Soc. exp. Biol., New York, 103:157-60, 1960.

4. GOBLE, F.C. South American Trypanosomes. In: Herman, R. \& Singer, J. Immunity to parasitic animals. New York, The Rockefeller University, 1970. p. 597-689.

5. HEBERT, W. J. Passive haemagglutination with special reference to the tanned cell technique. In: Weir, D. M. Handbook of experimental immunology. 3rd ed. Ox- ford, Blackwell Scientific Publications, 1979. p. 20. 1-20.20

6. LOWRY, O. H.; ROSEBROUGH, N. J.;FARR, A. L. \&RANDALL, R. J. Protein measurement with the Folin phenol reagent. $J$. biol. Chem., 193: 265-75, 1951.

7. RANGEL, H. A.; ARAOUJO, P. M. F.; CAMARGO, I. J. B.; BONFITTO, M.; REPKA, D.; SAKURADA, J. K. \& ATTA, A. M. Detection of a proteinase common to epimastigote, trypamastigote and amastigote of different strains of Trypanosoma cruzi, Tropenmed. Parasit., 32: 87-92, 1981.

8. RANGEL, H. A.; ARAOJO, P. M. F.; REPKA, D. \& COSTA, M. G. Trypanosoma cruzi: isolation and characterization of a proteinase. Exp. Parasit., 52: 199-209, 1981.

Recebido para publicaç̃ó em 07/08/84 A provado para publicação em 04/10/84 